\title{
Relationships among energy consumption, air pollution and economic growth in China
}

\author{
Li Song $^{1 *}$, Kalissa Fatoumata K ir ${ }^{1}$, Ping Shu ${ }^{1}$ \\ ${ }^{1}$ Economy and $\mathrm{M}$ anagement School, A nhui U niversity of Science and Technology, Huainan, PR China
}

\begin{abstract}
How to solve air pollution problerms in the process of economic development have arouse policy makers' attention in China. This paper examines the long-term relationships between industrial gas emission, energy consumption and economic growth in China from 1983 to 2014. Results show that both economic growth and energy consumption have significant effect on industrial gas emission for a long period. Energy consumption is the Granger causality of industrial gas emission at the $5 \%$ significant level, but not vice versa. Economic growth is also the Granger causality of industrial air emissions, but not vice versa. In the long term, it is essential to decrease energy consumption in order to attain high air quality. Making energy policy should pay attention to improve efficiency, so as to keep balance between economic growth, energy consumption and environmental protection. When making energy and economy policies, the government need to consider the relationship between energy consumption, economic development and atmospheric protection so as to seek a bal ance between energy, economy and environment protection.
\end{abstract}

\section{Introduction}

Since the reform and opening up, China's economy has been developed remarkably. The gross domestic product (GDP) has continuously increased from 6020.9 Billion yuan RMB (1983) [1] to 896915.6 billion yuan RMB (2015)[2]. Along with rapid economic development, energy consumption has kept expanding quickly, Annual energy consumption has risen from 627.70 million tons of coal equivalent in 1978 to 3318.48 million tons of coal equivalent in 2014[3]. In China's energy composition, coal plays an absolutely dominant role. In the nearly 30 years after the reform and opening up, more than half of energy consumption is coal [4]. Before the global financial crisis in 2008, China's economy as a whole was in a period of rapid development, which led to highspeed growth of energy demand. Along with rapid economic development and substantial increase in coal consumption, air pollution in China is becoming more and more serious. Large-scale deadliest smog events and air pollution disasters are becoming issues of national concern [5]. Occasional severe smog in some big cities and even regions indicate that air quality is on the brink of danger. Empirical statistics found that $85 \% \sim 90 \%$ of the total emission of sulfur dioxide comes from coal use, and sulfur dioxide emissions is of great significance to solve environmental problems, thus, how to keep balance between air quality, energy consumption and economic development is a key challenge for the government to be settled urgently.

It is necessary to study the relativity among economic growth, energy consumption and air pollution, so as to explore features and theory rules to support economy, environment and energy policies. This paper aims to analyze the air-energy-economy nexus from 1983 to 2014 in the same framework so as to provide some helpful suggestions for policy makers. The organization of the remainder of this paper is as follows. The next section briefly describes literature review. Section 3 describes methodology we used. Section 4 describes the main empirical findings. Finally, the summary and policy implications are outlined.

\section{A brief review of literature}

The relativity between environmental pollution and economic growth has attracted researchers' interest in recent years[6,7]. Grossman and Krueger (1991) [8]put forward the EKC hypothesis, which holds that in the early stage of economic development, carbon dioxide and other variables describing environmental deterioration will increase with the increase of per capita income,then, with the development of economy, these variables will decrease and finally reach a relatively stable state. The whole evolution process shows an inverted U-shaped curve. Many studies have tried to test the U-shaped curve based on data from different countries. Carbon dioxide and gross domestic product are the most frequently studied variables. J.Peng(2018)[9] found that economic scale expansion can accelerate the deterioration of the environment. In the economy-energy field, many studies explored the relativity between economic growth and energy consumption,but thoese results turned to be conflicting. Some studies found unidirectional causality either from energy consumption to economic growth or vice versa, while some

\footnotetext{
Corresponding author: 1468507309@qq.com
} 
researchers found bidirectional causality, even some studies found no causality at all. Bartleet et al.(2010)[10] found that energy consumption has co-integration relationship with economic growth, and economic activity determines the increase of the energy demand. X.P. Zhang et al. (2009) [11] found a one-way Granger causality from GDP to energy consumption and carbon emissions, but both energy consumption and carbon emissions are not Granger causality of economic growth. Y . L. Li et al. (2011) [12] used data from 30 provinces in China and found the real GDP per capita has long-run co-integration relationship with energy consumption. J. Liu et.al. (2018)[13] built a spatial and temporal decomposition model on the driving forces of energy consumption and emissions of carbon dioxide in China's cement industry from 2005 to 2012, and found that energy factors have a negative linear relationship with carbon dioxide emissions. X. Zhang (2015) [14] found that key high energy consuming industrial sectors directly lead to changes in air pollution through energy and economic policies.

Several researchers try to study the dynamic causal relativity between economic growth,energy consumption and environmental pollutants in one single framework. Arouri et al. (2012)[15] found a quadratic relationship between carbon dioxide emissions and energy consumption based on data from12 Middle East and North African Countries over the period 1981-2005. In conclusion, studies on energy-economy-environment field usually explore two factors such as energyeconomy and economy-environment, and usually choose carbon dioxide emissions as the air environmental variable, the direction of the causality between economic growth, energy consumption and air emissions is both methods and periods dependent.

\section{Methodology}

\subsection{Data}

The level of economic growth reflects the growth rate of a country's total economic volume in a certain period of time, and is a symbol of measuring a country's comprehensive economic strength.Here we use gross domestic product (GDP) to describe economic growth. Data of GDP is obtained from the China Statistical Yearbook from 1984 to 2015. Data of energy consumption can also be found in annual China Statistical Yearbook. Since industrial gas emissions are reliable data available during the period of study, we use industrial gas emissions as the variable describing air pollution. Data of industrial gas emission are adopted from the China Environmental Statistical Yearbook from 1984 to 2015. Industrial gas emission is measured in 100 million cu.m, energy consumption is measured in 10000 metric ton, and GDP is measured in billion yuan (RMB).
Cointegration relationship is usually used to prove the long-term relationship between several sets of sequences. Even if each sequence is nonstationary, however, by method of cointegration, we can establish a stable relationship between multiple sequences, so that we can make full use of the property of stationarity. Cointegration can avoid pseudo regression. If a group of non-stationary time series does not exist co integration relationship, then the regression model based on them may be pseudo regression. Before making cointegration test, all variables should be made unit root test and analyzed whether they are stationary and integrated of the same order. Then, Johansen cointegration tests method are analyzed to test whether there exists a longrun equilibrium relationships among the variables. Johansen's cointegration test using maximum likelihood estimation to test the cointegration relationship among variables in VAR system.

Set a VAR model with $\mathrm{k}$ lags as follows:

$$
y_{t}=A_{1} y_{t-1}+\ldots+A_{p} y_{t-p}+B x_{t}+\varepsilon_{t}(1)
$$

Where $x_{t}$ refers to economic growth $\left(\mathrm{L}_{\text {gdp }}\right)$ or energy consumption $\left(\mathrm{L}_{\text {ece }}\right), y_{t}$ refers to industrial gas emission $\left(\mathrm{L}_{\text {gas }}\right) . p$ is lagged rank of the model, $t$ is number of the sample. Matrix $A$ as well as matrix $B$ is the coefficient matrix to be estimated.

\subsection{Granger causality}

In short, Granger test is mainly used to test whether the variables $Y$ and $X$ are statistically causal. In the case of time series, the Granger causality between two variables $\mathrm{X}$ and $Y$ is defined as: if the past information of variables $\mathrm{X}$ and $Y$ is included, the prediction effect of variable $\mathrm{y}$ is better than that of $Y$ only by the past information of $Y$, that is, variable $\mathrm{x}$ helps to explain the future change of variable $Y$, then variable $\mathrm{X}$ is the Granger cause of variable $Y$ [16]. We first assume that there are two variables $Y$ and $\mathrm{X}$, and the corresponding lag forms are $Y_{t-i}$ and $X_{t-j}$. the test is to estimate the following two regressions:

$$
\begin{gathered}
y_{t}=\sum_{i=1}^{q} \alpha_{i} x_{t-i}+\sum_{j=1}^{q} \beta_{j} y_{t-j}+u_{1 t} \\
x_{t}=\sum_{i=1}^{s} \lambda_{i} x_{t-i}+\sum_{j=1}^{s} \delta_{j} y_{t-j}+u_{2 t}
\end{gathered}
$$

Where $\alpha_{i}, \beta_{j} \lambda_{i}$ and $\delta_{j}$ are constants, $u_{1 t}$ and $u_{2 t}$ are flat noise. So " $X$ is Granger Cause of $Y$ " is equivalent with not all constants $\left(\alpha_{i} \beta_{j} \lambda_{i}\right.$ and $\left.\delta_{j}\right)$ equal zero.

\subsection{Cointegration test}

\section{Results}




\subsection{Cointegration test results}

Unit root test is the test of the stability of the sequence. If the stability of the sequence is not tested, OLS will lead to pseudo regression. The premise of cointegration test is that each sequence is a single integer of the same order. The augmented Dickey-Fuller (ADF) is used to test the stability of the sequence. Table 1 shows ADF unit-root-test results, which proves that the null hypothesis are strongly rejected for level series, and all variables are stationary.

Table 1. ADF unit-root-test results on variables

\begin{tabular}{l|c|ccc}
\hline Series & ADF test value & \multicolumn{1}{|l}{$\begin{array}{l}\mathbf{1} \% \\
\text { value }\end{array}$} & $\begin{array}{l}\text { critical } \\
\text { value }\end{array}$ & critical \\
\hline $\mathrm{L}_{\text {gas }}$ & 1.58 & -3.66 & -2.96 \\
$\mathrm{~L}_{\text {ece }}$ & -0.12 & -3.67 & -2.96 \\
$\mathrm{~L}_{\text {gdp }}$ & -1.91 & -3.69 & -2.98 \\
\hline
\end{tabular}

Table 2. Optimal lag length test results

\begin{tabular}{c|c|c|c|cc}
\hline Lag & LogL & LR & AIC & SC & HQ \\
\hline 0 & -5.86 & NA & 0.59 & 0.73 & 0.64 \\
1 & 151.54 & 272.84 & -9.30 & -8.74 & -9.12 \\
2 & 168.34 & $25.75^{*}$ & $-9.82^{*}$ & $-8.84^{*}$ & $-9.51^{*}$ \\
\hline
\end{tabular}

Note:LR: sequential modified LR test statistic (each test at $5 \%$ level); AIC: A kaike information criterion;SC: Schwarz information criterion; HQ: Hannan-Quinn information criterion

Table 3. Results of Johannes's multivariate cointegration tests.

\begin{tabular}{c|c|c|cc}
\hline $\begin{array}{l}\text { Hypothesized } \\
\text { No. of CE(s) }\end{array}$ & Eigenvalue & $\begin{array}{l}\text { Trace } \\
\text { Statistic }\end{array}$ & $\begin{array}{l}\mathbf{0 . 0 5} \\
\text { Critical } \\
\text { Value }\end{array}$ & Prob.** \\
\hline None* & 0.61 & 34.12 & 24.27 & 0.00 \\
At most 1 & 0.20 & 7.00 & 12.32 & 0.32 \\
At most 2 & 0.01 & 0.37 & 4.13 & 0.60 \\
\hline
\end{tabular}

N ote: Trace test indicates 1 cointegrating eqn(s) at the 0.05 level;

* denotes rejection of the hypothesis at the 0.05 level

Owing to sensitivity of time series models to lag lengths, lag lengths selection tests including likelihoodratio statistic (LR), Akaike information criterion (AIC), Schwarz criterion (SC) and Hannan-Quinn information criterion (HQ) are made to determine the optimal lag length both for the cointegration test and the Granger causality test. As shown in Table 2, all the criteria suggest lags 2 is the optimal lag length. Table 3 presents the Johansen cointegration test results, which show that there exist one cointegrating relativity between economic growth,industrial gas emissions and energy consumption at the $5 \%$ significance level.

The cointegrating equation is specified as follows (standard error in parentheses):

$$
\begin{gathered}
\text { Lgas }=0.759 \mathrm{Lece}+0.307 \mathrm{Lgdp}(4) \\
\text { standard error } \quad(0.064) \quad(0.065)
\end{gathered}
$$

From the above cointegration equation, we can find that both economic growth and energy consumption have significant effects on industrial gas emissions in the long term. Suppose other factors remain unchanged, if energy consumption increases by $1 \%$, industrial gas emissions will increase by $0.759 \%$; if economic growth rate increases by $1 \%$, industrial gas emissions will increase by $0.307 \%$. Both economic consumption and economic growth have positive relativity with industrial gas emissions.

\subsection{Granger causality test results}

Granger causality test results are shown in Table 4. As shown in Table 4, when the null hypothesis is "Lece does not Granger Cause $L$ gas", the maximum $p$ value of the tests is smaller than 0.1 , thus the null hypothesis is rejected on control variables. That is to say, $L_{\text {ece }}$ is the Granger Cause of $\mathrm{L}_{\text {gas, }}$ There is a one-way Granger causality from energy consumption to industrial gas emissions at a significant level of $5 \%$. If energy consumption increases, industrial gas emissions will increase accordingly, but not vice versa. According to the same criterion, there is a one-way causal relativity between GDP and industrial gas emissions. If GDP increases, industrial gas emissions will increase accordingly, but not vice versa.

\begin{tabular}{|c|c|c|c|}
\hline \multirow[b]{2}{*}{ models } & \multicolumn{2}{|c|}{$\begin{array}{l}\text { Long-run causality test } \\
\text { results }\end{array}$} & \multirow{2}{*}{$\begin{array}{l}\text { Causality } \\
\text { decision }\end{array}$} \\
\hline & $\begin{array}{c}\mathrm{H}_{0}: \alpha_{1}=0 \\
\text { versus } \\
\mathrm{H}_{0}: \alpha_{1} \neq 0\end{array}$ & $\begin{array}{c}\mathrm{H}_{0}: \alpha_{2}=0 \\
\text { versus } \\
\mathrm{H}_{0}: \alpha_{2} \neq 0\end{array}$ & \\
\hline $\begin{array}{l}\text { L ece versus } \\
\quad L_{\text {gas }}\end{array}$ & $\begin{array}{l}9.873 \\
(0.003)\end{array}$ & $\begin{array}{l}1.525 \\
(0.295)\end{array}$ & $L_{\text {ece }} \rightarrow L_{\text {gas }}$ \\
\hline $\begin{array}{l}L_{\text {gdp }} \text { versus } \\
L_{\text {gas }}\end{array}$ & $\begin{array}{l}4.391 \\
(0.033)\end{array}$ & $\begin{array}{l}0.762 \\
(0.646)\end{array}$ & $L_{\text {gdp }} \rightarrow L_{\text {gas }}$ \\
\hline $\begin{array}{c}L_{\text {gdp }} \text { versus } \\
L_{\text {ece }}\end{array}$ & $\begin{array}{l}1.822 \\
(0.222)\end{array}$ & $\begin{array}{c}9.71 \\
(0.004)\end{array}$ & $\mathrm{L}_{\text {gdp }} \rightarrow \mathrm{L}_{\text {ece }}$ \\
\hline
\end{tabular}

Table 4.Annotation of this table

The maximum $\mathrm{p}$ value of the tests is 0.004 when the null hypothesis is "Lece does not Granger Cause Lgdp", then the null hypothesis are rejected, that is to say, there is a one-way Granger causality from GDP to energy consumption. If energy consumption increases, GDP will increase accordingly, but not vice versa. As to the null hypothesis " $\mathrm{L}_{\text {gdp }}$ does not Granger Cause $\mathrm{L}_{\text {gas }}$ ", the maximum $p$ value of the tests is 0.033 , which is smaller than 0.1 . then the null hypothesis is rejected on control variables. That is to say, $\mathrm{L}_{\text {gdp }}$ does Granger Cause $\mathrm{L}_{\text {gas }}$, There is a unidirectional Granger causality running from energy consumption to industrial gas emission at the 5\% significant level. If GDP increases, industrial gas emission will increase accordingly, but not vice versa. It carries an implication, that is, as the inportant resouce and motivation of economic development, energy 
comsumption also has a role in aggravating air pollution. Higher gross domestic product is associated with higher consumption of coal, oil, fertilizers and other energy , as well as industrial air emissions.

\section{Discussion}

We find that industrial gas emission has a long-term causal relationship with both energy consumption and economic growth from 1983 to 2014 in China. It is important to point out the causality direction of variables for policy-making. As there is one-way causality from energy consumption to GDP, energy consumption is the leading variable of economic growth, which means China economy heavily depends on energy consumption. Hence, any policy to reduce energy consumption may have a negative impact on the country's economic growth. There is causality from GDP to industrial gas emission, which implies that economic growth may affect industrial gas emission, the root of air environment problems lies in the economic growth mode and energy consumption mode. When making economic growth and energy policies, policy makers must pay attention to the possible environmental impacts of these policies in order to balance economic development, energy consumption and environmental protection. In recent years, China government has been promoting and carrying out energy structure reform, gradually reducing the proportion of coal consumption.

\section{Conclusion}

This paper uses Johansen cointegration test and Granger causality test to investigates the relationtivity between industrial air emissions, energy consumption and economic growth based on data in China. Our results carry several policy implications.

Firstly, there exists a one-way causality from industrial air emissions to energy consumption and economic growth. In the long term, it is essential to decrease energy consumption to improve air quality. Energy consumption policy should focus on improving efficiency for ensuring economic growth as well as air quality.

Secondly, the increase of energy consumption will also lead to the continuous increase of industrial air emissions. So it is important for the policy makers to coordinate energy policies and environmental policies.

Finally, the prevention and control of air pollution is a complex and lasting systematic project. It is necessary to coordinate economic policy with energy consumption policy and environmental policy.

\section{References}

1. China Statistical Bureau. China Statistical Yearbook 1983. Beijing: China Statistical Publishing House (1984)
2. China Statistical Bureau. China Statistical Y earbook 2015. Beijing: China Statistical Publishing House (2016)

3. National Bureau of Statistics, Ministry of Ecological Environment. China statistical yearbook on environment 2015, Beijing: China Statistical Publishing House (2016)

4. D. B. Lorente, M. Shahbaz, D. R oubaud, S. Farhani, How economic growth, renewable electricity and natural resources contribute to $\mathrm{CO}_{2}$ emissions? Energy Policy, 113, 356-367 (2018)

5. H. Hu, X. Zhang, L.Lin, The interactions between China's economic growth, energy production and consumption and the related air emissions during 2000-2011, Ecological Indicators, 46,38-51 (2014)

6. Shaojian Wang, Qiuying Li, Chuanglin Fang, Chunshan Zhou. The relationship between economic growth, energy consumption, and $\mathrm{CO} 2$ emissions: Empirical evidence from China, Science of The Total Environment, 542, 360-371 (2016)

7. U mesh Bastola, Pratikshya Sapkota.Relationships among energy consumption, pollution emission, and economic growth in Nepal. Energy, 80, 254-262 (2015)

8. Grossman, G. M. and Krueger, A. B. Environmental Impacts of the North A merican Free Trade A greement. N BER W orking Paper, N o. 3914 (1991)

9. J. Peng, Y. Zhang, R. Xie, Y. Liu, A nalysis of driving factors on China@sir pollution emissions from the view of critical supply chains, Journal of Cleaner Production, 203, 197-209 (2018)

10. M. Bartleet, R. Gounder, Energy consumption and economic growth in New Zealand: Results of trivariate and multivariate models,E nergy Policy, 38, 3508-3517 (2010)

11. X.P. Zhang, X.M. Cheng.Energy consumption, carbon emissions, and economic growth in China Ecological Economics, 68, 2706-2712 (2009)

12. Y. L. Li, M. Y. Han, S. Y. Liu, G. Q. Chen. Energy consumption and greenhouse gas emissions by buildings: A multi-scale perspective. Building and Environment, 151, 240-250 (2019)

13. J. Liu, S. Zhang, F. W agner, Exploring the driving forces of energy consumption and environmental pollution in China@rement industry at the provincial level, J ournal of Cleaner Production, 184, 274-285 (2018)

14. Y .Zhang, H. Wang, S. L iang, M. Xu, Q. Zhang, H. Zhao, J. Bi, A dual strategy for controlling energy consumption and air pollution in China@metropolis of Beijing, Energy, 81, 294-303 (2015)

15. M. E. H. A rouri, A. B. Y oussef, H. M chreni, C. Rault, Energy consumption, economic growth and $\mathrm{CO} 2$ emissions in Middle East and North A frican countries, Energy Policy, 45,342-349 (2012)

16. A.H.Studenmund. Applied Econometrics. Beijing: M achinery Industry Press ( 2007) 